\title{
Reação de cultivares de cana-de-açúcar à broca do colmo
}

\author{
Leila Luci Dinardo-Miranda $\left({ }^{1 *}\right)$; Juliano Vilela Fracasso (2); Viviane Pereira da Costa (1); \\ Ivan Antonio dos Anjos ( $\left.{ }^{1}\right)$; Diego Olympio Peixoto Lopes ( $\left.{ }^{2}\right)$ \\ (') Instituto Agronômico, Centro de Cana-de-açúcar, Rodovia SP 333, km 321, 14001-970 Ribeirão Preto (SP), Brasil. \\ (2) Faculdade de Ciências Agrárias e Veterinárias de Jaboticabal (UNESP), Departamento de Defesa Fitossanitária, \\ Rodovia de Acesso Prof. Paulo Donato Castellane, s/n, 14884-900 Jaboticabal (SP), Brasil. \\ (*) Autora correspondente: leiladinardo@iac.sp.gov.br
}

Recebido: 3/out./2011; Aceito: 18/fev./2013

\begin{abstract}
Resumo
O objetivo do presente trabalho foi avaliar a reação de dez cultivares de cana-de-açúcar à Diatraea saccharalis Fabr., em experimento desenvolvido em delineamento em blocos casualizados com seis repetições e tratamentos em esquema fatorial 2x10. O primeiro fator foi constituído por dois níveis de infestação de broca (infestado e não infestado), e o segundo fator, pelas dez cultivares de cana-de-açúcar em estudo (IAC87-3396, IAC91-1099, IACSP93-3046, IACSP94-2101, IACSP94-2094, IACSP94-4004, IACSP95-5000, IACSP96-3060, IACSP96-2042 e SP91-1115). O ensaio foi avaliado em dois ciclos da cultura, cana-planta e primeira soca. Todas as cultivares foram muito atacadas pela broca, sendo IACSP94-4004, IACSP96-2042 e SP91-1115 as mais infestadas e danificadas pelo inseto. Para cana-planta, parcelas infestadas pela broca tiveram maior teor de fibra que parcelas não infestadas. Para soqueira, parcelas infestadas produziram 10\% menos, com menores teores de pureza e maiores teores de açúcares redutores totais que as não infestadas.
\end{abstract}

Palavras-chave: Saccharum sp., Diatraea saccharalis, resistência de plantas a insetos, produtividade, análise tecnológica.

\section{Reaction of sugarcane cultivars to sugarcane borer}

\section{Abstract}

The objective of this study was to evaluate the reaction of ten sugarcane cultivars to Diatraea saccharalis under field conditions, using a randomized block design with treatments in factorial $2 \times 10$ with six replications. The first factor was represented by two levels of infestation (infested and not infested) by borer and the second one, by the ten sugarcane varieties (IAC87-3396, IAC91-1099, IACSP93-3046, IACSP94-2101, IACSP94-2094, IACSP94-4004, IACSP95-5000, IACSP96-3060, IACSP96-2042 and SP91-1115). The experiment was evaluated in two crop cycles: plant crop and first ratoon. All cultivars were attacked by the borer, being IACSP94-4004, IACSP96-2042 and SP91-1115 the most damaged cultivars with the highest infestation index. During the plant crop, plots infested by the borer presented higher fiber content than the ones not infested. During the first ratoon, non infested plants produced 10\% less and presented lower purity and higher content of reducing sugars than the non-infested plants.

Key words: Saccharum sp., Diatraea saccharalis, plant resistande to insects, yield, technological analysis.

\section{INTRODUÇÃO}

A broca da cana Diatraea saccharalis Fabr. (Lepidoptera: Crambidae) é uma das mais importantes pragas da cana-de-açúcar no Brasil, por reduzir significativamente a produtividade em campo e a qualidade da matériaprima (Dinardo-Miranda, 2008). Trabalhos realizados na Copersucar com cultivares cultivadas no fim da década de 1990 revelaram que, a cada 1\% de intensidade de infestação da broca, as perdas poderiam chegar a $1,50 \%$ na produtividade de colmos, $0,49 \%$ na produtividade de açúcar e $0,28 \%$ na produtividade de álcool
(Arrigoni, 2002). Apesar da importância econômica de D. saccharalis, são raras as informaçôes quanto à suscetibilidade/resistência contra o inseto nas cultivares atualmente utilizadas no Brasil. Em trabalho mais recente, Demetrio et al. (2008) avaliaram os danos causados pela broca em algumas cultivares, sob infestaçóes naturais no Paraná, e registraram diferenças entre as 12 cultivares estudadas quanto às populaçóes de broca no interior dos colmos, sendo RB875338 e RB72454 as mais infestadas.

Trabalhando com dez cultivares em casa de vegetação, Dinardo-Miranda et al. (2012) verificaram 
que a cultivar IAC86-3396 foi a preferida pela broca para oviposição, enquanto as cultivares IACSP94-2101 e IACSP96-2042 foram não preferidas. Esses autores também verificaram que, entre as cultivares avaliadas, IACSP94-2094 foi a mais desfavorável para a entrada e o desenvolvimento das lagartas no interior dos colmos, revelando o menor índice de intensidade de infestação.

Embora no Brasil o manejo de áreas infestadas esteja embasado no controle biológico, especialmente envolvendo o parasitóide de lagartas Cotesia flavipes (Cameron) (Hymenoptera: Braconidae) (Dinardo-Miranda, 2008), informaçóes sobre o comportamento de cultivares em relação ao ataque da broca são imprescindíveis, pois orientam a escolha de locais para levantamentos populacionais e liberaçôes de parasitóides. Além disso, o uso de cultivares resistentes é ferramenta bastante útil nos programas de manejo integrado (LARA, 1991; SMITH, 2005). Nessa linha, o presente trabalho teve por objetivo avaliar a reaçáo de dez cultivares de cana-de-açúcar em relaçáo à D. saccharalis.

\section{MATERIAL E MÉTODOS}

O ensaio foi desenvolvido no Centro de Cana IAC, em Ribeirāo Preto (SP), a $21^{\circ} 12^{\prime} 55,63^{\prime \prime} S, 47^{\circ} 52^{\prime} 37,58^{\prime \prime} \mathrm{W}$ e $630 \mathrm{~m}$ de altitude, utilizando o delineamento experimental em blocos casualizados em esquema fatorial 2 x 10 com 6 repetiçóes, sendo o primeiro fator constituído por 2 níveis de infestação de $D$. saccharalis (infestado e não infestado), e o segundo fator constituído por dez cultivares de cana-de-açúcar, sendo elas IAC87-3396, IAC911099, IACSP93-3046, IACSP94-2101, IACSP94-2094, IACSP94-4004, IACSP95-5000, IACSP96-3060, IACSP96-2042, oriundas do Programa de Melhoramento Genético de Cana-de-açúcar do IAC e liberadas para plantio comercial e SP91-1115, utilizada como padrão devido à sua suscetibilidade à praga (Dinardo-Miranda et al., 2012).

Cada parcela foi constituída por quatro sulcos de $4 \mathrm{~m}$ de comprimento, em espaçamento de $1,5 \mathrm{~m}$, totalizando $24 \mathrm{~m}^{2}$. O plantio foi feito em $17 / 3 / 2009$, com a primeira colheita realizada em 12/8/2010 (dezessete meses depois do plantio), e a segunda realizada em 12/7/2011 (11 meses de idade da cultura).

As infestações de broca na cana-planta foram feitas em quatro ocasióes, sendo a primeira em 12/8/09, quando a cultura estava com cinco meses de idade e as plantas já tinham os primeiros entrenós formados. As demais infestaçóes foram feitas em 1.\%10/09, 5/11/09 e 22/12/09. Em cada ocasiáo, foram colocadas quatro posturas de tamanho médio (aproximadamente cem ovos) por linha de cana, prendendo as folhas de papel às folhas das plantas, na região próxima ao ponto de fixação da bainha. Desta forma, em cana-planta, cada parcela foi infestada com 16 posturas ou aproximadamente 1600 ovos por parcela.

Nas parcelas não infestadas efetuaram-se três aplicaçóes do inseticida triflumuron 480SC, na dose de $80 \mathrm{~mL} \mathrm{ha}^{-1}$, em 20/7/09, 10/9/09 e 23/10/09, visando reduzir eventuais populaçóes do inseto.

Em cana-soca, as infestaçóes seguiram o mesmo protocolo descrito para cana-planta e foram realizadas em 17/11/2010, 15/12/2010, 13/1/2011 e 23/3/2011. A fim de evitar populaçóes da praga nas parcelas não infestadas em cana-soca, foram feitas duas aplicaçóes do inseticida rynaxypyr 350WG, na dose de $60 \mathrm{~g} \mathrm{ha}^{-1}$, em 26/11/2010 e $3 / 2 / 2011$.

Durante o período de desenvolvimento vegetativo da cana-planta e da soqueira, foram feitos levantamentos para determinar os índices de intensidade de infestação em cada parcela, expressos em porcentagem de entrenós brocados. Em cana-planta, o levantamento foi feito em 18/11/2009 e na soqueira, em 12/5/2011. Para tanto, em cada um dos levantamentos, coletaram-se três colmos por linha (doze colmos por parcela), que foram rachados longitudinalmente ao meio, para contagem do número total de entrenós e número de entrenós brocados.

Imediatamente antes das colheitas do ensaio, coletaram-se doze colmos de cada parcela (três colmos por linha), os quais foram abertos longitudinalmente, avaliando-se os números de entrenós totais e os números de entrenós brocados, parâmetros utilizados para estimativa da intensidade de infestação final. Em seguida, estes colmos foram utilizados para análise dos parâmetros tecnológicos, sendo entáo determinados os teores de pol, fibra, açúcares redutores e pureza da cana, adotando-se o método do pagamento de cana pelo teor de sacarose (Fernandez, 2001). Para a estimativa da produtividade, todos os colmos de cada parcela foram cortados e pesados.

Para análise estatística, os dados de intensidade de infestação foram transformados em arc seno $(\mathrm{x} / 100)^{0,5}$, por se tratar de dados em porcentagem. Após análise de variância pelo teste $\mathrm{F}$, as médias foram comparadas pelo teste de Tukey a 5\% de significância utilizando o software SAS (SAS INSTITUTE, 2000).

\section{RESULTADOS E DISCUSSÃO}

Considerando-se as amostragens feitas durante o desenvolvimento vegetativo, verificaram-se índices de intensidade de infestação superiores nas parcelas infestadas em relação às não infestadas em todas as cultivares, tanto para cana-planta $(18 / 11 / 2009)$ como para soqueira (12/5/2011). A exceção foi a cultivar IAC91-1099, em cana-planta (Tabelas 1 e 2). Apesar disso, na média, as parcelas infestadas tiveram índices de intensidade de infestação de broca significativamente maiores que nas parcelas não infestadas (Tabelas 1 e 2). $\mathrm{O}$ fato de 
se observar nas parcelas infestadas e não infestadas colmos brocados indica que a população natural da praga na área do ensaio era elevada, mantendo-se significativa mesmo após a aplicação de inseticidas. Em adição, a obtenção de índices de intensidade de infestação de até $10 \%$ em parcelas tratadas, sugere que as aplicações de inseticidas não foram suficientes para manter as parcelas não infestadas livres da praga.

$\mathrm{Na}$ colheita da cana-planta, o índice médio de intensidade de infestação das parcelas não infestadas foi superior ao observado em novembro (Tabela 1), indicando que o inseticida não exercia mais efeito sobre a praga e que as condiçóes ambientais eram favoráveis ao desenvolvimento das populaçóes do inseto. $\mathrm{Na}$ soqueira, as populações mantiveram-se semelhantes entre maio (primeira amostragem) e julho (colheita), com ligeiro crescimento nas parcelas tratadas com inseticida (Tabela 2).

Em cana-planta, considerando os dados médios (Tabela 1), verifica-se que as cultivares infestadas pela broca foram mais produtivas do que as não infestadas. Tomando-se cada cultivar isoladamente (Tabela 1), em poucos casos as diferenças de produtividade entre parcelas infestadas e não infestadas foram significativas. Um olhar atento a este resultado revela não um possível efeito benéfico da broca sobre a produtividade, mas um efeito prejudicial do inseticida. É provável que as três aplicaçóes de triflumuron nas parcelas não infestadas tenham prejudicado o desenvolvimento da cultura, reduzindo sua produtividade em relação às parcelas não tratadas.

O efeito da praga sobre a produtividade foi mais evidente na soqueira (Tabela 2), quando algumas cultivares (IACSP93-3046, IACSP91-2101, IACSP95-5000 e IACSP96-3046) tiveram produtividades superiores nas parcelas não infestadas pela broca, em comparação com as parcelas infestadas.

Considerando-se a média de todas as cultivares na soqueira, a infestação pela broca reduziu a produtividade em cerca de $10 \%$ (Tabela 2). Deve-se lembrar, entretanto, que o dano médio causado pela broca no presente ensaio foi maior que este, pois, mesmo em parcelas não infestadas artificialmente com ovos de $D$. saccharalis houve altas populaçóes da praga e, consequentemente, elevado valor de intensidade de infestação.

Tabela 1. Intensidade de infestação em novembro de 2009 ( $\mathrm{II}_{\text {nov }}$ ) e na colheita (II col $)$, produtividade de colmos (TCH), pol na cana (PCC), fibra na cana (fibra), pureza na cana (pureza), açúcares redutores na cana (ARC) e produtividade de açúcar (TPH) obtidos na colheita da cana-planta, em função da infestação (I) ou não (NI) com Diatraea saccharalis

\begin{tabular}{|c|c|c|c|c|c|c|c|c|c|}
\hline Cultivar & Inf. & $\mathrm{II}_{\text {nov }}$ & $\mathrm{II}_{\mathrm{col}}$ & TCH & PCC & Fibra & Pureza & ARC & TPH \\
\hline \multirow{2}{*}{ IAC87-3396 } & I & $7,1 \mathrm{a}$ & $8,3 \mathrm{a}$ & $241 \mathrm{a}$ & $16,64 \mathrm{a}$ & $12,61 \mathrm{a}$ & 90,87 a & $0,44 \mathrm{a}$ & $40,3 \mathrm{a}$ \\
\hline & $\mathrm{NI}$ & $0,9 b$ & $3,7 \mathrm{~b}$ & $232 \mathrm{a}$ & 16,59 a & $11,58 \mathrm{~b}$ & $89,65 \mathrm{a}$ & $0,48 \mathrm{a}$ & $38,4 \mathrm{a}$ \\
\hline \multirow{2}{*}{ IAC91-1099 } & 1 & $6,7 \mathrm{a}$ & $8,8 \mathrm{a}$ & $236 a$ & $15,34 \mathrm{a}$ & $11,16 \mathrm{a}$ & 89,51 a & $0,49 a$ & $36,6 \mathrm{a}$ \\
\hline & $\mathrm{NI}$ & $4,9 a$ & $7,4 \mathrm{a}$ & $225 \mathrm{a}$ & $16,56 \mathrm{~b}$ & $10,45 \mathrm{~b}$ & $90,26 \mathrm{a}$ & $0,47 a$ & $37,4 \mathrm{a}$ \\
\hline \multirow{2}{*}{ IACSP93-3046 } & 1 & $8,0 \mathrm{a}$ & $9,3 \mathrm{a}$ & $197 a$ & $17,36 \mathrm{a}$ & $11,59 a$ & 90,55 a & $0,46 \mathrm{a}$ & $34,5 \mathrm{a}$ \\
\hline & $\mathrm{NI}$ & $1,2 \mathrm{~b}$ & $4,6 \mathrm{~b}$ & $173 \mathrm{a}$ & 17,69 a & $11,20 \mathrm{a}$ & $90,65 \mathrm{a}$ & $0,46 a$ & $31,0 \mathrm{a}$ \\
\hline \multirow{2}{*}{ IACSP94-2101 } & 1 & $7,5 \mathrm{a}$ & $11,2 \mathrm{a}$ & $273 a$ & $17,51 \mathrm{a}$ & $11,92 \mathrm{a}$ & $91,17 \mathrm{a}$ & $0,44 a$ & $48,0 \mathrm{a}$ \\
\hline & $\mathrm{NI}$ & $2,0 \mathrm{~b}$ & $4,4 \mathrm{~b}$ & $232 b$ & $17,33 \mathrm{a}$ & $11,47 \mathrm{a}$ & $90,58 \mathrm{a}$ & $0,46 a$ & $40,1 \mathrm{a}$ \\
\hline \multirow{2}{*}{ IACSP94-2094 } & I & $9,8 \mathrm{a}$ & $7,7 \mathrm{a}$ & $230 \mathrm{a}$ & $16,38 \mathrm{a}$ & $12,08 \mathrm{a}$ & $90,91 \mathrm{a}$ & $0,44 \mathrm{a}$ & $37,6 \mathrm{a}$ \\
\hline & $\mathrm{NI}$ & $0,6 \mathrm{~b}$ & $5,1 \mathrm{~b}$ & $195 \mathrm{a}$ & $16,47 \mathrm{a}$ & $11,61 \mathrm{a}$ & $91,65 \mathrm{a}$ & $0,42 \mathrm{a}$ & $31,8 \mathrm{a}$ \\
\hline \multirow{2}{*}{ IACSP94-4004 } & 1 & $15,3 \mathrm{a}$ & $11,8 \mathrm{a}$ & $179 a$ & $13,94 \mathrm{a}$ & $11,35 \mathrm{a}$ & $82,87 \mathrm{a}$ & $0,68 \mathrm{a}$ & $25,2 \mathrm{a}$ \\
\hline & $\mathrm{NI}$ & $1,7 \mathrm{~b}$ & $6,4 \mathrm{~b}$ & $228 b$ & $15,21 \mathrm{~b}$ & $11,07 \mathrm{a}$ & 87,17 b & $0,56 \mathrm{~b}$ & 19,1 a \\
\hline \multirow{2}{*}{ IACSP95-5000 } & I & $19,4 \mathrm{a}$ & $9,1 \mathrm{a}$ & $237 a$ & $17,31 \mathrm{a}$ & $11,76 \mathrm{a}$ & $90,45 \mathrm{a}$ & $0,46 \mathrm{a}$ & $41,3 \mathrm{a}$ \\
\hline & $\mathrm{NI}$ & $10,1 \mathrm{~b}$ & $7,2 \mathrm{a}$ & $224 \mathrm{a}$ & $17,63 \mathrm{a}$ & $11,50 \mathrm{a}$ & $91,75 \mathrm{a}$ & $0,42 \mathrm{a}$ & $39,4 \mathrm{a}$ \\
\hline \multirow{2}{*}{ IACSP96-3060 } & 1 & $9,6 \mathrm{a}$ & $8,0 \mathrm{a}$ & $178 \mathrm{a}$ & $14,64 \mathrm{a}$ & $11,24 \mathrm{a}$ & $88,14 a$ & $0,53 a$ & $30,2 \mathrm{a}$ \\
\hline & $\mathrm{NI}$ & $1,0 \mathrm{~b}$ & 5,9 a & $166 \mathrm{a}$ & $16,90 \mathrm{~b}$ & $11,02 \mathrm{a}$ & $91,67 \mathrm{~b}$ & $0,43 \mathrm{~b}$ & $24,0 \mathrm{a}$ \\
\hline \multirow{2}{*}{ IACSP96-2042 } & I & $12,2 \mathrm{a}$ & $10,1 \mathrm{a}$ & $235 \mathrm{a}$ & $16,00 \mathrm{a}$ & $10,37 \mathrm{a}$ & $91,64 \mathrm{a}$ & $0,43 a$ & $37,8 \mathrm{a}$ \\
\hline & $\mathrm{NI}$ & $1,6 \mathrm{~b}$ & $5,3 \mathrm{~b}$ & $241 \mathrm{a}$ & $16,83 \mathrm{~b}$ & $10,53 \mathrm{a}$ & $91,80 \mathrm{a}$ & $0,43 a$ & $40,4 \mathrm{a}$ \\
\hline \multirow{2}{*}{ SP91-1115 } & 1 & $16,2 \mathrm{a}$ & $10,0 \mathrm{a}$ & $248 \mathrm{a}$ & $16,04 \mathrm{a}$ & $10,54 \mathrm{a}$ & $89,30 \mathrm{a}$ & $0,50 \mathrm{a}$ & $40,3 \mathrm{a}$ \\
\hline & $\mathrm{NI}$ & $1,3 b$ & $8,9 \mathrm{a}$ & $216 a$ & $16,89 b$ & $10,39 a$ & $89,76 \mathrm{a}$ & $0,49 a$ & $36,7 \mathrm{a}$ \\
\hline \multirow{2}{*}{ Média } & I & $11,2 \mathrm{a}$ & $9,4 \mathrm{a}$ & $225 \mathrm{a}$ & $16,37 \mathrm{a}$ & $11,46 \mathrm{a}$ & $89,90 \mathrm{a}$ & $0,47 a$ & $37,18 \mathrm{a}$ \\
\hline & $\mathrm{NI}$ & $2,3 \mathrm{~b}$ & $5,9 \mathrm{~b}$ & $203 b$ & 16,59 a & $11,09 \mathrm{~b}$ & $90,14 \mathrm{a}$ & $0,47 a$ & $33,81 \mathrm{a}$ \\
\hline \multirow[t]{2}{*}{ CV (\%) } & & 43,7 & 17,5 & 18,1 & 11,2 & 5,3 & 3,3 & 9,7 & 18,3 \\
\hline & Bloco & $1,67^{\mathrm{NS}}$ & $1,20^{\mathrm{NS}}$ & $1,90^{\mathrm{NS}}$ & $0,64^{\mathrm{NS}}$ & $1,26^{\mathrm{NS}}$ & $0,85^{\mathrm{NS}}$ & $0,81^{\mathrm{NS}}$ & $1,49^{\mathrm{NS}}$ \\
\hline \multirow{3}{*}{$\begin{array}{l}\text { Valores } \\
\text { de F }\end{array}$} & Variedade (V) & $5,52^{*}$ & $2,15^{*}$ & $8,63^{* *}$ & $2,49^{* *}$ & $10,28^{* *}$ & $4,32^{* *}$ & $4,29 * *$ & $18,21^{* *}$ \\
\hline & Infestação (I) & $151,89^{* *}$ & $62,87^{* *}$ & $9,83^{* *}$ & $0,45^{\mathrm{NS}}$ & $12,03^{* *}$ & $0,19^{\mathrm{NS}}$ & $0,05^{\mathrm{NS}}$ & $11,52^{* *}$ \\
\hline & $V^{*} \mid$ & $1,07^{\mathrm{NS}}$ & $1,93^{*}$ & $0,61^{\mathrm{NS}}$ & $0,79^{\mathrm{NS}}$ & $0,88^{\mathrm{NS}}$ & $1,19^{\mathrm{NS}}$ & $1,14^{\mathrm{NS}}$ & $2,15^{*}$ \\
\hline
\end{tabular}

$\mathrm{II}_{\text {nov }}$ e II $\mathrm{Iol}_{\text {col }}$ : em porcentagem de entrenós brocados; $\mathrm{TCH}$ : t colmos ha ${ }^{-1}$; PCC: pol\%cana; fibra: fibra\%cana; pureza: pureza\%cana; ARC: açúcares redutores\%cana; TPH: t pol ha- ${ }^{-1}$.

NS, ${ }^{*} \mathrm{e}^{* *}$ indicam valores não significativos, significativos a $5 \%$ de probabilidade de significativos a $1 \%$ de probabilidade, respectivamente.

Para uma mesma cultivar, médias na mesma coluna seguidas por letras iguais nâo diferem entre si pelo teste de Tukey $(\mathrm{p}<0,05)$. 
Tabela 2. Intensidade de infestação em maio de 2011 ( II $_{\text {mai }}$ ) e na colheita (II ${ }_{\text {col }}$ ), produtividade de colmos (TCH), pol na cana (PCC), fibra na cana (fibra), pureza na cana (pureza), açúcares redutores na cana (ARC) e produtividade de açúcar (TPH) obtidos na colheita da cana-planta, em função da infestação (I) ou não (NI) com Diatraea saccharalis

\begin{tabular}{|c|c|c|c|c|c|c|c|c|c|}
\hline Cultivar & Inf. & II $_{\text {mai }}$ & $\mathrm{II}_{\mathrm{col}}$ & TCH & PCC & Fibra & Pureza & ARC & TPH \\
\hline \multirow{2}{*}{ IAC87-3396 } & I & $8,8 \mathrm{a}$ & $6,8 \mathrm{a}$ & $120 \mathrm{a}$ & $14,47 \mathrm{a}$ & $12,46 \mathrm{a}$ & 83,32 a & $0,66 \mathrm{a}$ & $17,4 \mathrm{a}$ \\
\hline & $\mathrm{NI}$ & $3,5 \mathrm{~b}$ & $6,2 \mathrm{a}$ & $120 \mathrm{a}$ & $14,71 \mathrm{a}$ & $12,32 \mathrm{a}$ & $83,64 \mathrm{a}$ & $0,65 \mathrm{a}$ & $17,7 \mathrm{a}$ \\
\hline \multirow{2}{*}{ IAC91-1099 } & I & $11,3 \mathrm{a}$ & $10,9 a$ & $140 \mathrm{a}$ & $14,43 \mathrm{a}$ & $11,45 \mathrm{a}$ & 93,97 a & $0,65 \mathrm{a}$ & $20,2 \mathrm{a}$ \\
\hline & $\mathrm{NI}$ & $4,0 \mathrm{~b}$ & $5,8 \mathrm{~b}$ & $146 a$ & $15,02 \mathrm{a}$ & $11,90 \mathrm{a}$ & $86,53 \mathrm{a}$ & $0,57 \mathrm{a}$ & $21,9 \mathrm{a}$ \\
\hline \multirow{2}{*}{ IACSP93-3046 } & I & $10,0 \mathrm{a}$ & $8,2 \mathrm{a}$ & $111 \mathrm{a}$ & $15,15 a$ & $12,01 \mathrm{a}$ & $83,88 \mathrm{a}$ & $0,65 \mathrm{a}$ & $16,8 \mathrm{a}$ \\
\hline & $\mathrm{NI}$ & $7,0 \mathrm{~b}$ & $7,1 \mathrm{a}$ & $140 \mathrm{~b}$ & $15,08 \mathrm{a}$ & $11,72 \mathrm{a}$ & $84,51 \mathrm{a}$ & $0,63 \mathrm{a}$ & $21,2 \mathrm{~b}$ \\
\hline \multirow{2}{*}{ IACSP94-2101 } & 1 & $7,7 \mathrm{a}$ & $7,7 \mathrm{a}$ & $128 \mathrm{a}$ & $15,08 \mathrm{a}$ & $12,22 \mathrm{a}$ & $82,31 \mathrm{a}$ & $0,69 a$ & $19,3 \mathrm{a}$ \\
\hline & $\mathrm{NI}$ & $2,7 b$ & $3,9 \mathrm{~b}$ & $169 \mathrm{~b}$ & $14,89 \mathrm{a}$ & $12,03 \mathrm{a}$ & $81,64 \mathrm{a}$ & $0,71 \mathrm{a}$ & $25,2 \mathrm{~b}$ \\
\hline \multirow{2}{*}{ IACSP94-2094 } & I & $9,4 \mathrm{a}$ & $8,6 \mathrm{a}$ & $136 a$ & $15,31 \mathrm{a}$ & $12,84 \mathrm{a}$ & 88,89 a & $0,49 a$ & $20,8 \mathrm{a}$ \\
\hline & $\mathrm{NI}$ & $1,9 \mathrm{~b}$ & 5,9 a & $143 a$ & $15,59 \mathrm{a}$ & $12,82 \mathrm{a}$ & $89,14 \mathrm{a}$ & $0,49 a$ & $22,2 \mathrm{a}$ \\
\hline \multirow{2}{*}{ IACSP94-4004 } & I & $10,9 \mathrm{a}$ & $12,9 \mathrm{a}$ & $105 \mathrm{a}$ & $14,27 \mathrm{a}$ & $11,36 \mathrm{a}$ & $77,65 \mathrm{a}$ & $0,83 \mathrm{a}$ & $15,0 \mathrm{a}$ \\
\hline & $\mathrm{NI}$ & $6,6 b$ & 9,9 a & $96 \mathrm{a}$ & $13,76 \mathrm{a}$ & $11,61 \mathrm{a}$ & 79,40 a & $0,78 \mathrm{a}$ & $12,4 \mathrm{a}$ \\
\hline \multirow{2}{*}{ IACSP95-5000 } & 1 & $8,8 \mathrm{a}$ & $9,7 \mathrm{a}$ & $142 \mathrm{a}$ & $15,14 \mathrm{a}$ & $11,60 \mathrm{a}$ & $83,76 \mathrm{a}$ & $0,65 a$ & $21,6 a$ \\
\hline & $\mathrm{NI}$ & $8,3 \mathrm{~b}$ & $4,6 \mathrm{~b}$ & $174 b$ & $15,34 \mathrm{a}$ & $11,81 \mathrm{a}$ & $84,91 \mathrm{a}$ & $0,62 \mathrm{a}$ & $26,8 \mathrm{~b}$ \\
\hline \multirow{2}{*}{ IACSP96-3060 } & I & 9,0 a & $9,6 \mathrm{a}$ & $78 \mathrm{a}$ & $14,90 \mathrm{a}$ & $11,52 \mathrm{a}$ & $86,86 \mathrm{a}$ & $0,56 \mathrm{a}$ & $11,7 \mathrm{a}$ \\
\hline & $\mathrm{NI}$ & $4,9 b$ & $5,0 \mathrm{~b}$ & $120 \mathrm{~b}$ & $15,13 a$ & $11,61 \mathrm{a}$ & $87,78 \mathrm{a}$ & $0,54 \mathrm{a}$ & $18,1 \mathrm{~b}$ \\
\hline \multirow{2}{*}{ IACSP96-2042 } & I & $13,1 \mathrm{a}$ & $13,4 \mathrm{a}$ & $138 a$ & $15,63 a$ & $11,28 \mathrm{a}$ & 87,78 a & $0,54 a$ & $21,5 \mathrm{a}$ \\
\hline & $\mathrm{NI}$ & $8,0 \mathrm{~b}$ & $8,8 \mathrm{~b}$ & $139 a$ & $15,45 \mathrm{a}$ & $10,81 \mathrm{a}$ & $88,44 \mathrm{a}$ & $0,52 \mathrm{a}$ & $21,5 \mathrm{a}$ \\
\hline \multirow{2}{*}{ SP91-1115 } & I & $10,6 \mathrm{a}$ & $12,0 \mathrm{a}$ & $72 \mathrm{a}$ & $13,10 \mathrm{a}$ & $10,94 \mathrm{a}$ & 81,62 a & $0,72 \mathrm{a}$ & $10,2 \mathrm{a}$ \\
\hline & $\mathrm{NI}$ & $7,3 \mathrm{~b}$ & $8,0 \mathrm{~b}$ & $79 a$ & $13,87 \mathrm{a}$ & $10,11 \mathrm{a}$ & $82,65 \mathrm{a}$ & $0,70 \mathrm{a}$ & 9,9 a \\
\hline \multirow{2}{*}{ Média } & I & $10,0 \mathrm{a}$ & $10,0 \mathrm{a}$ & $118 \mathrm{a}$ & $14,75 \mathrm{a}$ & $11,77 \mathrm{a}$ & $84,00 \mathrm{a}$ & $0,65 \mathrm{a}$ & $17,44 a$ \\
\hline & $\mathrm{NI}$ & $5,4 b$ & $6,5 b$ & $131 \mathrm{~b}$ & $14,89 \mathrm{a}$ & $11,67 \mathrm{a}$ & $84,85 b$ & $0,62 b$ & $19,69 \mathrm{~b}$ \\
\hline CV(\%) & & 27,7 & 21,3 & 18,3 & 5,6 & 4,4 & 2,5 & 9,7 & 19,5 \\
\hline \multirow{4}{*}{$\begin{array}{l}\text { Valores } \\
\text { de F }\end{array}$} & Bloco & $1,80^{\mathrm{NS}}$ & $4,20^{* *}$ & $2,01^{\mathrm{NS}}$ & $2,55^{\mathrm{NS}}$ & $0,52^{\mathrm{NS}}$ & $12,30^{* *}$ & $12,11^{* *}$ & $11,24^{* *}$ \\
\hline & Variedade (V) & $3,08^{* *}$ & $4,13^{* *}$ & $15,33^{* *}$ & $7,31^{* *}$ & $19,24^{* *}$ & $27,51^{* *}$ & $27,91^{* *}$ & $12,40^{* *}$ \\
\hline & Infestação (I) & $52,33^{* *}$ & $33,78^{* *}$ & $9,94^{* *}$ & $0,82^{\mathrm{NS}}$ & $1,00^{\mathrm{NS}}$ & $4,95^{*}$ & $4,54^{*}$ & $8,05^{* *}$ \\
\hline & $V^{*} I$ & $1,25^{\mathrm{NS}}$ & $0,87^{\mathrm{NS}}$ & $2,34^{* *}$ & $0,64^{\mathrm{NS}}$ & $1,61^{\mathrm{NS}}$ & $0,52^{\mathrm{NS}}$ & $0,61^{\mathrm{NS}}$ & $0,78^{\mathrm{NS}}$ \\
\hline
\end{tabular}

II e II : em porcentagem de entrenós brocados; TCH: t colmos ha ${ }^{-1}$; PCC: pol\%cana; fibra: fibra\%cana; pureza: pureza\%cana; ARC: açúcares redutores\%cana; TPH: t pol ha ${ }^{-1}$. NS, ${ }^{*} \mathrm{e}^{* *}$ indicam valores não significativos, significativos a $5 \%$ de probabilidade de significativos a $1 \%$ de probabilidade, respectivamente.

Para uma mesma cultivar, médias na mesma coluna seguidas por letras iguais năo diferem entre si pelo teste de Tukey $(\mathrm{p}<0,05)$.

Considerando que, na média, parcelas infestadas contêm $10 \%$ de entrenós brocados e produtividade de $118 \mathrm{t} \mathrm{ha}^{-1}$, enquanto as não infestadas, $6,5 \%$ de entrenós brocados e $131 \mathrm{t} \mathrm{ha}^{-1}$ de produtividade (Tabela 2), pode-se inferir que, para este estudo, $3,5 \%$ de entrenós brocados resultaram em redução de $10 \%$ na produtividade de colmos. Desta forma, cada $1 \%$ de entrenós brocados resultou em $2,9 \%$ de redução de produtividade. Este índice é maior que o estimado por outros pesquisadores para cultivares mais antigas. Precetti et al. (1988) e Teran et al. (1988), em estudos envolvendo cinco cultivares cultivadas na década de 1980 , determinaram que a cada $1 \%$ de entrenós brocados por D. saccharalis, haveria redução média de $0,8 \%$ na produtividade de colmos. Arrigoni (2002), trabalhando com cultivares cultivadas na década de 1990, revelou que a cada $1 \%$ de entrenós brocados as perdas poderiam chegar a $1,5 \%$ na produtividade de colmos. Assim, os dados revelam uma tendência das cultivares mais modernas serem mais suscetíveis à broca do que as antigas. Possíveis explicações para isso podem estar relacionadas ao melhoramento genético que, buscando cultivares mais produtivas e ricas em açúcar, selecionou genótipos mais suscetíveis à praga.

Tanto para cana-planta como para soqueira e considerando-se parcelas infestadas e não infestadas, apenas algumas cultivares diferiram entre si com relação aos parâmetros tecnológicos (Tabelas 1 e 2). Em cana-planta, foram constatados maiores teores de açúcar (pol\%cana, PCC) em parcelas não infestadas em cinco das dez cultivares (Tabela 1). Nestas cultivares, nas parcelas infestadas havia em média 11,5\% menos açúcar do que nas parcelas não infestadas. Em poucas cultivares, entretanto, houve diferenças significativas em relação aos teores de fibra, pureza e açúcares redutores (Tabela 1 ).

$\mathrm{Na}$ soqueira, considerando cada cultivar isoladamente, não foram observadas diferenças entre parcelas infestadas e não infestadas pela broca em relaçáo aos parâmetros tecnológicos avaliados (Tabela 2).

$\mathrm{Na}$ média de todas as cultivares, em cana-planta foram observadas diferenças entre as parcelas infestadas e as não infestadas pela broca em relação ao teor de fibra (Tabela 1) e na soqueira, em relaçáo aos teores de pureza e açúcares redutores totais (Tabela 2). 
Estes dados confirmam informaçóes de alguns autores (VAlsechi et al., 1976; Precetti et al., 1988), os quais observaram que ataques de broca resultaram em menores quantidades de açúcar nos colmos, representado pelo PCC (pol\%cana), menores teores de pureza, maiores teores de fibra (fibra\%cana) e maiores teores de açúcares redutores totais.

Trabalhando com seis cultivares de cana-de-açúcar, em área naturalmente infestada por $D$. saccharalis, no Estado de Louisiana, EUA, White et al. (2008) também verificaram que os teores de pureza e de açúcar nos colmos foram mais elevados nas parcelas tratadas com inseticidas e, consequentemente menos atacadas pela praga, do que nas parcelas não tratadas.

No presente estudo, não foram observadas diferenças em relação a todos os parâmetros tecnológicos, entre as cultivares infestadas e não infestadas, porque mesmo nas parcelas não infestadas artificialmente pela broca havia entrenós brocados por ocasiáo da colheita (Tabelas 1 e 2). Em alguns casos, os índices de infestação nas parcelas não infestadas foram pouco inferiores aos das parcelas infestadas (Tabelas 1 e 2). Nos trabalhos de Precetti et al. (1988) e Teran et al. (1988), os colmos analisados tinham intensidade de infestação variando de 0 a $50 \%$ de entrenós brocados, o que permitiu estudar mais adequadamente a interferência do ataque da broca sobre os parâmetros tecnológicos da matéria prima.

O maior teor de fibra (cana-planta), menor teor de pureza e maior teor de açúcares redutores (cana-soca) nas parcelas infestadas pela broca confirmam os danos causados pela praga à qualidade da matéria prima.

A produtividade de açúcar por hectare $\left(\mathrm{TPH}, \mathrm{t} \mathrm{ha}^{-1}\right)$ pode ser inferida multiplicando a produtividade de colmos (TCH) pelo teor de açúcar nos colmos (PCC). Visto que na cana-planta, parcelas não infestadas artificialmente pela broca produziram menos que as não infestadas, provavelmente devido a um efeito negativo do inseticida, não foi possível avaliar o efeito da praga sobre a produtividade de açúcar naquele ciclo da cultura (Tabela 1). Na soqueira, entretanto, as perdas de açúcar devido às infestaçôes de broca foram significativas nas cultivares IACSP93-3046, IACSP91-2101, IACSP95-5000 e IACSP96-3060 (Tabela 2).

$\mathrm{Na}$ soqueira, em média, parcelas infestadas pela broca produziram 11,4\% menos açúcar por hectare do que parcelas não infestadas (Tabela 2).

Enquanto nas parcelas infestadas havia $10 \%$ de entrenós brocados e produtividade de pol de 14,44 $\mathrm{t} \mathrm{ha}^{-1}$, nas não infestadas foram observados $6,5 \%$ de entrenós brocados e 19,69 $\mathrm{t} \mathrm{ha}^{-1}$ de pol (Tabela 2), de onde se pode inferir que $3,5 \%$ de entrenós brocados resultaram em redução de $11,4 \%$ na produtividade de açúcar. Assim, cada $1 \%$ de entrenós brocados provocou 3,3\% de redução de produtividade de açúcar. Este resultado é superior ao encontrado por WHITE et al. (2008), que trabalharam com cultivares da Louisiana, EUA, e obtiveram 18\% de intensidade de infestação nas parcelas não tratadas com inseticida, resultando em $11 \%$ de perda de açúcar.ha ${ }^{-1}$. Os autores estimaram que, em média, a cada $1 \%$ de entrenós brocados ocorria $0,61 \%$ de redução de açúcar por hectare.

As perdas em açúcar causadas pela broca, estimadas neste trabalho, também são superiores às calculadas por TERAn et al. (1988), que avaliaram quatro cultivares de cana plantadas no Estado de Sáo Paulo, na década de 1980, e estimaram que a cada $1 \%$ de entrenós brocados ocorria $0,21 \%$ de redução na produtividade de açúcar. Posteriormente, ARRIGONI (2002), estudando cultivares plantadas no fim dos anos 1990, também em São Paulo, estimou que as perdas de açúcar poderiam atingir 0,49\% a cada $1 \%$ de entrenós brocados. Estes dados indicam que as cultivares atualmente liberadas para plantio comercial são, em geral, mais suscetíveis à broca do que as cultivadas no passado, como anteriormente discutido.

De fato, considerando somente os dados das parcelas infestadas com ovos de $D$. saccharalis e não tratadas com inseticidas, observados por ocasiáo das colheitas da cana-planta e da soqueira, verifica-se que não há diferenças significativas entre as novas cultivares testadas e a SP91-1115 (Tabela 3). Embora todas as cultivares tenham recebido ovos da praga, a ocorrência de elevados níveis de danos nas parcelas náo infestadas e tratadas com inseticida revelam que a população de D. saccharalis no local do ensaio era bastante alta. Assim, esta população natural infestou livremente todas as cultivares, e não foram observadas diferenças significativas entre as novas cultivares e o padrão suscetível (Tabela 3). Este fato também foi observado quando foram considerados os dados médios dos dois ciclos da cultura (Tabela 3).

$\mathrm{O}$ valor médio para as duas colheitas, entretanto, revelou diferenças entre as cultivares. As cultivares IACSP94-4004, IACSP92-2042 e SP91-1115 foram as mais danificadas pela broca, com intensidades de infestação maiores à da cultivar IAC97-3396, a menos danificada. Dinardo-Miranda et al. (2012), trabalhando

Tabela 3. Intensidade de infestação (II, porcentagem de entrenós brocados) nas colheitas da cana-planta e da soqueira e média dos dois ciclos da cultura, nas parcelas infestadas e não tratadas com inseticidas

\begin{tabular}{lccc|} 
Cultivar & Cana-planta & Cana-soca & Média \\
\hline IAC87-3396 & $8,3 \mathrm{a}$ & $6,8 \mathrm{a}$ & $7,5 \mathrm{~b}$ \\
\hline IAC91-1099 & $8,8 \mathrm{a}$ & $10,9 \mathrm{a}$ & $9,8 \mathrm{ab}$ \\
\hline IACSP93-3046 & $9,4 \mathrm{a}$ & $8,2 \mathrm{a}$ & $8,8 \mathrm{ab}$ \\
\hline IACSP94-2101 & $11,2 \mathrm{a}$ & $7,7 \mathrm{a}$ & $9,4 \mathrm{ab}$ \\
\hline IACSP94-2094 & $7,8 \mathrm{a}$ & $8,6 \mathrm{a}$ & $8,2 \mathrm{ab}$ \\
\hline IACSP94-4004 & $11,8 \mathrm{a}$ & $13,0 \mathrm{a}$ & $12,4 \mathrm{a}$ \\
\hline IACSP95-5000 & $9,1 \mathrm{a}$ & $9,7 \mathrm{a}$ & $9,4 \mathrm{ab}$ \\
\hline IACSP96-3060 & $8,0 \mathrm{a}$ & $9,6 \mathrm{a}$ & $8,8 \mathrm{ab}$ \\
\hline IACSP96-2042 & $10,1 \mathrm{a}$ & $13,4 \mathrm{a}$ & $11,7 \mathrm{a}$ \\
\hline SP91-1115 & $10,0 \mathrm{a}$ & $12,0 \mathrm{a}$ & $11,0 \mathrm{a}$ \\
\hline
\end{tabular}

Médias na mesma coluna seguidas por letras iguais nẫo diferem entre si pelo teste de Tukey $(\mathrm{p}<0,05)$. 
em casa de vegetação com as mesmas cultivares, também relataram que IACSP94-4004, IACSP92-2042 e SP911115 estavam entre as cultivares mais infestadas por $D$. saccharalis. Entretanto, aqueles autores verificaram que IACSP94-2094 foi a de menor intensidade de infestação, sendo considerada por eles a cultivar mais desfavorável para a entrada e o desenvolvimento das lagartas no interior dos colmos, com menores danos devidos ao ataque de D. saccharalis. No presente trabalho, IACSP94-2094 teve comportamento intermediário enquanto os menores danos foram observados na cultivar IAC87-3396.

Pinto et al. (2006) consideram que infestações superiores a $1 \%$ ou $2 \%$ causam prejuízos econômicos à cultura. Assim, os resultados de presente ensaio permitem concluir que, embora haja diferenças entre as cultivares quanto à reação à $D$. saccharalis, todas elas são suscetíveis à praga.

\section{CONCLUSÃO}

Todas as cultivares são atacadas pela broca, sendo IACSP94-4004, IACSP96-2042 e SP91-1115 as mais infestadas e danificadas pelo inseto. Em cana-planta, parcelas infestadas pela broca possuem maior teor de fibra que parcelas não infestadas. $\mathrm{Na}$ soqueira, plantas infestadas produzem $10 \%$ menos, com menores teores de pureza e maiores teores de açúcares redutores totais que as não infestadas.

\section{AGRADECIMENTOS}

À Fundação de Amparo à Pesquisa do Estado de Sáo Paulo (FAPESP), pelo auxílio financeiro para o desenvolvimento do trabalho (processo 09/00661-1) e à empresa de controle biológico, BIOCONTROL, pelo fornecimento de posturas de D. saccharalis.

\section{REFERÊNCIAS}

ARRIGONI, E.B. Broca da cana-de-açúcar: Importância econômica e situação atual. In: ARRIGONI, E.B.; DINARDOMIRANDA, L.L.; ROSSETO, R. Pragas da cana-de-açúcar:
Importância econômica e enfoques atuais. Piracicaba: STAB/IAC/ CTC, 2002. (CD-ROM).

DEMETRIO, P.A.; ZONETTI, P.P.; MUNHOZ, R.E.F. Avaliação de clones de cana-de-açúcar promissores RBs quanto à resistência à broca da cana (Diatraea saccharalis) na região noroeste do Paraná. Iniciação Científica Cesumar, v.10, p.13-16, 2008.

DINARDO-MIRANDA, L.L. Pragas. In: DINARDOMIRANDA, L.L.; VASCONCELOS, A.C.M.; LANDELL, M.G.A. (Ed.). Cana-de-açúcar. Campinas: Instituto Agronômico, 2008. p.349-404.

DINARDO-MIRANDA, L.L.; ANJOS, I.A.; COSTA, V.P.; FRACASSO, J.V. Sugarcane cultivars to sugarcane borer. Pesquisa Agropecuária Brasileira, v.47, p.1-7, 2012.

FERNANDEZ, A.C. Cálculos na agroindústria da cana-de-açúcar. Piracicaba: Edição do autor, 2001. 215p.

LARA, F.M. Princípios de resistência de plantas a insetos. 2.ed. São Paulo: Ícone, 1991. 336p.

PINTO, A.S.; CANO, M.A.V.; SANTOS, E.M. A Broca da cana, Diatraea saccharalis. In: PINTO, A.S. Controle de pragas da canade-açúcar. Sertãozinho: Biocontrol, 2006. p.15-20.

PRECETTI, A.A.C.M.; TERÁN, F.O.; SANCHEZ, A.G. Alteraçôes nas características tecnológicas de algumas cultivares de cana-de-açúcar, devidas ao dano da broca Diatraea saccharalis. Boletim Técnico Copersucar, v.40, p.3-8, 1988.

SAS INSTITUTE (CARY, NC). SAS/STAT: User's guide, version 8.1. Cary 2000. v.1. 943p.

SMITH, C.M. Plant resistance to arthropods - Molecular and conventional approaches. The Netherlands: Springer, 2005. 423p.

TERÁN, F.O.; SANCHEZ, A.G.; PRECETTI, A.A.C.M. Estudos sobre resistência da cana à broca em telado - IV. Boletim Técnico Copersucar, v.40, p.9-14, 1988.

VALSECHI, O.; OLIVEIRA, E.R.; BARBIN, D.; NOVAES, F.W. Estudos sobre alguns efeitos da broca (Diatraea saccharalis Fabr.) na cana-de-açúcar e seus reflexos na indústria açucareira. Piracicaba: ESALQ/Departamento de Tecnologia Rural, 1976. 140p.

WHITE, W.H.; VIATOR, R.P.; DUFRENE, E.O.; DALLEY, C.D.; RICHARD JR, E.P.; TEW, T.L. Re-evaluation of sugarcane borer (Lepidoptera: Crambidae) bioeconomics in Luisiana. Crop Protection, v.27, p.1256-1261, 2008. 